\title{
Propagação vegetativa via miniestaquia caulinar seriada e produtividade de minijardim de espécies de Tibouchina spp.
}

\begin{tabular}{llr}
\hline Leandro Porto Latoh & $\begin{array}{l}\text { Programa de Pós-Graduação em Produção Vegetal da Universidade Federal do } \\
\text { Paraná (UFPR). }\end{array}$ & E-mail: leandrolatoh@outlook.com \\
\hline July Franchesca Dallagrana & Universidade Positivo (UP, PR). & E-mail: arq.julydallagrana@hotmail.com \\
\hline Deborah Cristina Portes & Universidade Federal do Paraná (UFPR) & E-mail: deborahcportes@gmail.com \\
\hline Renata de Almeida Maggioni & Programa de Pós-Graduação em Produção vegetal da Universidade Federal do \\
\hline Katia Christina Zuffellato-Ribas & Universidade Federal do Paraná (UFPR). & E-mail: remaggioni89@gmail.com \\
\hline
\end{tabular}

Recebido em: 7 junho 2017. Aceito em: 2 maio 2018.

DOI: http://dx.doi.org/10.21674/2448-0479.43.343-357

\section{Resumo}

Espécies da família Melastomataceae, são recomendadas para recomposição de diversos ecossistemas, estando presentes em diversos biomas brasileiros. O presente trabalho objetivou estudar o enraizamento de quatro espécies de Tibouchina ( $T$. aff. fothergillae, $T$. heteromalla, $T$. moricandiana var. vinaceae e $T$. sellowiana) e quantificar a produtividade do minijardim. A partir de um minijardim consolidado no outono (maio/2015) em Curitiba-PR, o material vegetal foi coletado nos meses de setembro/2015(C1), novembro/2015(C2), janeiro/2016(C3) e março/2016(C4). As miniestacas foram confeccionadas com $6+1 \mathrm{~cm}$ de comprimento, mantendo-se um par de folhas reduzidas à metade. Os propágulos foram plantados em tubetes com vermiculita e substrato comercial na proporção $1: 1(\mathrm{v} / \mathrm{v})$, mantidos em casa de vegetação climatizada. As avaliações ocorreram após 35dias, considerando-se as variáveis: porcentagem de enraizamento, calos, sobrevivência, mortalidade, manutenção das folhas iniciais, brotações, número e comprimento médio de raízes/miniestaca. As espécies estudadas não apresentaram diferença estatística nas diferentes coletas, apresentando altos índices de enraizamento adventício, salvo T. sellowiana. Para $T$. aff. fothergillae, $T$. moricandiana var. vinaceae e $T$. heteromalla podem ser consideradas espécies de fácil enraizamento. $T$. sellowiana, considerada uma espécie de difícil enraizamento, tem seu potencial rizogênico aumentado pela técnica de rejuvenescimento seriado. A produtividade de brotos/minicepa foi superior a 5 brotos/minicepa para todas as espécies, salvo $T$. sellowiana que apresentou 3,10 
brotos/minicepa. Já para produtividade de miniestacas/broto todas as espécies apresentaram resultados superiores a 1,60, salvo T.sellowiana com 1,38. Conclui-se que para as espécies estudadas a técnica de miniestaquia é recomendada, principalmente para $T$. sellowiana. Para produtividade de brotos e miniestacas recomenda-se a coleta do material vegetal em momentos com temperatura média mais elevadas.

Palavras-chave: Espécies nativas. Rejuvenescimento. Rizogênese.

\section{Abstract \\ Plant Propagation by Mini-Cuttings Technique and Mini-Garden Productivity for Species of Tibouchina spp. Melastomataceae family's species,} are recommended for the recomposition of several ecosystems, because they're present in almost all Brazilian biomes. The objective of this work was to study the rooting of four Tibouchina species ( $T$. aff.fothergillae, T.heteromalla, T.moricandiana var. vinaceae and T.sellowiana) and quantifying the productivity of the ministamps. The vegetable material was collected in the months of September/2015(C1), November/2015(C2), January/2016(C3) and March/2016(C4). The minicuttings were made with $6 \mathrm{~cm}$ of length, maintaining a pair of leaves reduced in half. The propagules were planted in tubes with vermiculite of fine granulometry and commercial substrate in the proportion $1: 1(\mathrm{v} / \mathrm{v})$, keeping in a greenhouse. The evaluations were made after 35 days, considering the following variables: rooting percentage, number and mean root length/minicutting, percentage of minicuttings with calluses, survival, mortality, percentage of initial leaves maintenance, and bud minicutting. All species studied didn't present statistical differences in the different collections, with high adventitious rooting rates, except $T$. sellowiana, which presented the lowed results. T.aff. fothergillae, $T$. moricandiana var. vinaceae and $T$. heteromalla can be considered easy species rooting. $T$. sellowiana, considered a hard specie rooting, has it has its rizogenic potential increased by the serial rejuvenation technique. The productivity of buds/ministamp was higher than 5 buds/ministamp for all species, except to T.sellowiana, which presented 3.10 buds/ministamp. However, for productivity of minicutting/bud all species showed results above 1.60, excepted $T$. sellowiana with 1.38. For Tibouchina species are recommended minicutting technic, especially to $T$. sellowiana. For bud and minicutting production are recommended collect vegetal material in moments with high temperatures.

Keywords: Native species, Rejuvenation, Rizogenic. 


\section{Introdução}

A família Melastomataceae é composta por árvores, arbustos e trepadeiras lenhosas. Apresenta distribuição pantropical, possuindo cerca de 166 gêneros e 4570 espécies (CLAUSING; RENNER, 2001). Dentre os 166 gêneros da família Melastomataceae, o gênero Tibouchina é encontrado principalmente na Cordilheira dos Andes e no Brasil, onde sua distribuição ocorre na região sudeste (PERALTA, 2002).

Tibouchina affinis fothergillae Cogn., conhecida como Quaresmeira, é uma espécie de habito arbustivo, com altura variando de 1 a 2,5 metros, ramos jovens quadrangulares e os mais velhos tomando a forma subcilíndrica, folhas elíptico-lanceolada, ápice agudo e base obtusa, flores pentâmeras e pétalas de coloração púrpura (MEYER, 2008).

Tibouchina heteromalla Cogn., cujo nome comum é Orelha de Onça, apresenta hábito arbustivo variando de 1 a 2 metros de altura. Quando jovens, os ramos se apresentam na forma quadrangular, posteriormente passando pra subcilíndricos diminutamente alados, com folhas ovais e ápice agudo a obtuso, base cordada, margem crenulada, apresentando flores pentâmeras, pétalas roxas, obovadas, ápice obtuso a truncado (MEYER, 2008).

Tibouchina moricandiana variedade vinaceae Baill., conhecida também por Quaresmeira, é classificada como arbusto, variando entre 1,5 a 3 metros de altura, muito ramificado, com folhas pubescentes e ovaladas avermelhadas, inflorescência curta apresentando flores de coloração vinho, as quais florescem ao longo do ano (LORENZI, 2008).

Tibouchina sellowiana Cogn., chamada popularmente de Manacá da Serra, é classificada com arvoreta com altura variando de 2 a 8 metros de altura. Apresenta ramos quadrangulares, posteriormente subcilindricos, folhas elípticas, ápice agudo e base aguda, margem esparsa a moderadamente estrigosa, flores pentâmeras, pétalas inicialmente brancas que posteriormente tornam-se róseas a purpúreas (MEYER, 2008).

Seu uso está associado a ornamentação, devido ao porte reduzido e se aplica perfeitamente em projetos paisagísticos de pequeno porte, além de seu alto potencial de reflorestamento e recuperação em áreas degradadas. Está distribuída geograficamente nos estados de Minas Gerais, Rio de Janeiro, São Paulo e Paraná (SILVA; AFFONSO, 2005).

Segundo Moraes et al. (2000), espécies do gênero Tibouchina apresentam importante papel no biomonitoramento da floresta atlântica. Além disso, o gênero apresenta floradas duradouras e abundantes, inferindo beneficamente na nutrição e manutenção de diferentes do gênero Apis (RENNER, 1989). Pelo fato das espécies Melastomataceae apresentarem grande número de sementes abortadas e baixa taxa de germinação (César et al., 2009), a utilização de métodos que envolvam a propagação vegetativa é justificada

A técnica de propagação vegetativa via miniestaquia, é um desmembramento da estaquia convencional. Utiliza propágulos oriundos de minicepas seminais ou materiais em constante processo 
de rejuvenescimento, advindo da poda periódica das plantas matrizes, respondendo com maior índice de enraizamento adventício de seus propágulos, sem uso de reguladores vegetais, por conta do acúmulo de ácido indol acético (IAA) sintetizado naturalmente nas regiões meristemáticas (HARTMANN et al., 2011). Segundo Stuepp et al. (2016), em estudo com propagação vegetativa via miniestaquia caulinar de Acer palmatum Trunb., a técnica é factível para a espécie, uma vez que esta apresenta elevado percentual de enraizamento com uso de propágulos de $8 \pm 1 \mathrm{~cm}$ de comprimento.

Badilla et al. (2016), comparando a eficiência do enraizamento via miniestaquia caulinar de Tectona grandis L.f. com uso de diferentes concentrações de IBA (0, 1000, 2000, 4000, 8000 e 16000 $\mathrm{mg} \mathrm{L}^{-1}$ ), concluíram que o uso de IBA é desnecessário para propagação da espécie, apresentando a mesma $91,8 \%$ de enraizamento.

O objetivo do presente trabalho foi estudar o enraizamento e verificar se o rejuvenescimento seriado potencializa a rizogênese de quatro espécies de Tibouchina (Tibouchina aff. fothergillae, $T$. heteromalla, T. moricandiana var. vinaceae e $T$. sellowiana), a partir da técnica de propagação vegetativa via miniestaquia caulinar seriada, utilizando propágulos oriundos de minicepas cultivadas em minijardim, bem como mensurar produtividade do minijardim ao longo das diferentes coletas.

\section{Material e Métodos}

\section{Miniestaquia caulinar de quatro espécies de Tibouchina}

O experimento foi conduzido em casa de vegetação climatizada, com temperatura média de $25^{\circ} \mathrm{C} \pm 2^{\circ} \mathrm{C}$ e umidade relativa do ar UR $=85 \%$, localizada no Setor de Ciências Biológicas, da Universidade Federal do Paraná (UFPR), em Curitiba- PR, apresentando clima caracterizado como Cfb, segundo a classificação de Koppen-Geiger (PELL; FINLAYSON; MCMAHON, 2007).

Miniestacas caulinares de quatro espécies de Tibouchina ( $T$ aff. fothergillae, $T$. heteromalla, T.moricandiana var. vinaceae e T. sellowiana) foram coletadas a partir de um minijardim formado por minicepas originadas na estação do outono (maio/2015) pela técnica de estaquia caulinar convencional, sendo o mesmo localizado em área de pleno sol do Laboratório de Macropropagação da Universidade Federal do Paraná (UFPR).

A primeira coleta (C1: setembro/2015 transição entre o inverno e primavera) de miniestacas ocorreu cerca de 120 dias após o período de aclimatação das minicepas em área de pleno sol, sendo as posteriores coletas planejadas de acordo com a produtividade de brotações das minicepas, para confecção de miniestacas, sendo estimado um intervalo entre coleta/instalação de 35 a 40 dias, num total de quatro coletas (C2: novembro/2015 primavera, C3: janeiro/2016 verão, C4: março/2016 transição entre o verão e o outono). 
Os propágulos foram confeccionados com $6 \mathrm{~cm} \pm 1 \mathrm{~cm}$ de comprimento e diâmetro médio de $0,21 \mathrm{~cm}$, com corte em bisel na base e reto na porção apical, mantendo-se um par de folhas reduzidas a metade de sua superfície original no ápice caulinar, posteriormente plantados em tubetes de $53 \mathrm{~cm}^{3}$ com 6 estrias, preenchidos com vermiculita de granulometria fina e substrato comercial (Tropstrato $^{\circledR}$ ) na proporção 1:1 (v/v) (Figura 1).

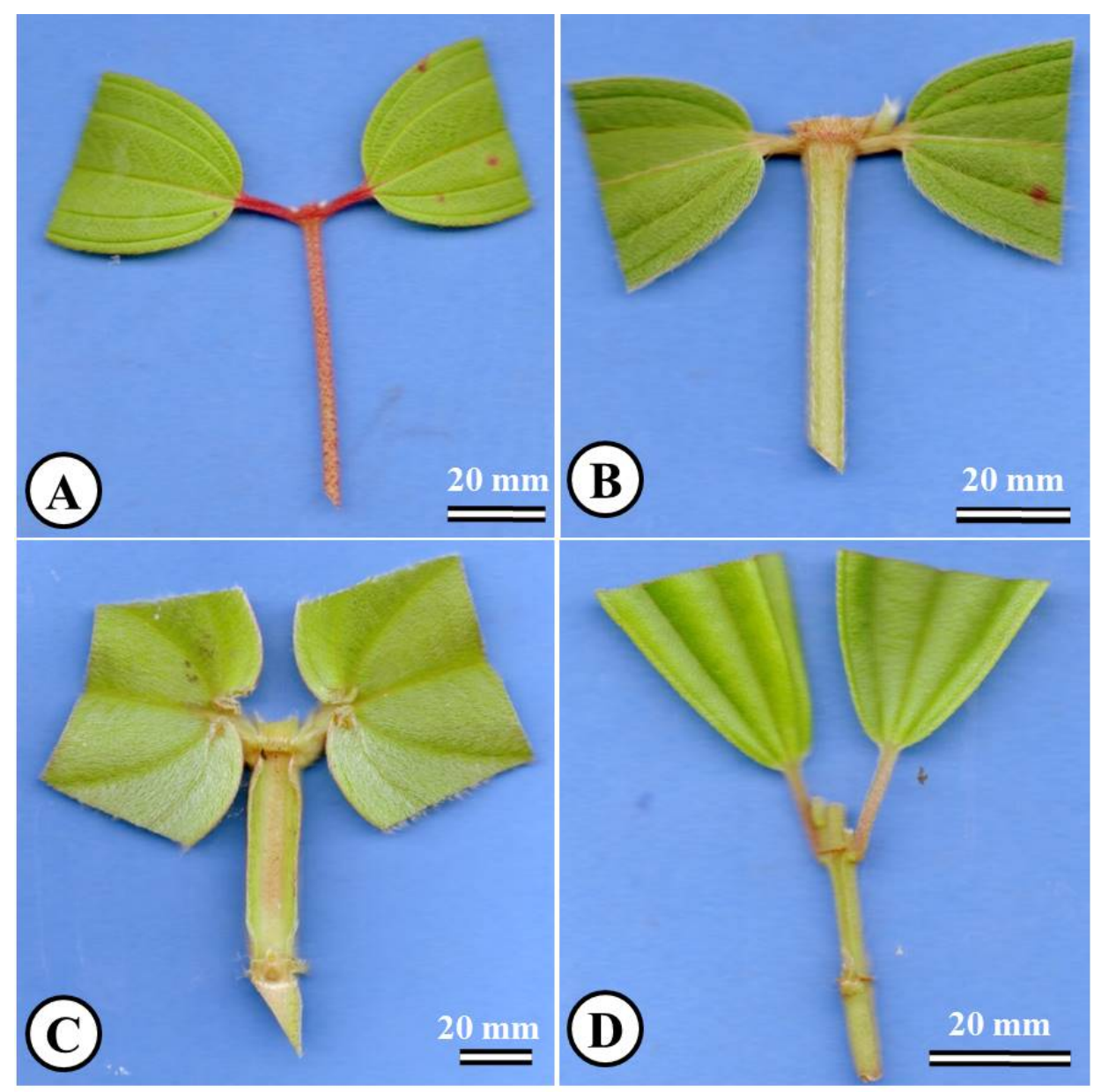

Figura 1: Exemplares de propágulos utilizados na técnica de miniestaquia caulinar, sendo: $A-T$. moricandiana var. vinaceae; B - T. aff. fothergillae; C - T. heteromalla e D - T. sellowiana, CuritibaPR.

Decorridos 35 dias, foram avaliadas as seguintes variáveis: porcentagem de enraizamento (ME) (miniestacas que estavam vivas e emitiram raízes de, no mínimo, $2 \mathrm{~mm}$ de comprimento), número médio de raízes/miniestaca (NR), comprimento médio das 3 maiores raízes/miniestaca (CM), porcentagem de miniestacas com calos (MC) (miniestacas vivas sem raízes, que emitiram massa de células indiferenciadas na região basal), porcentagem de miniestacas vivas (MV) (miniestacas que não emitiram raízes e nem massa de células indiferenciadas na região basal), porcentagem de 
miniestacas mortas (MM), porcentagem de miniestacas que mantiveram as folhas iniciais (MMF) e porcentagem de miniestacas brotadas (MB).

Não foram utilizados reguladores vegetais para indução rizogênica por se tratar de material vegetal rejuvenescido. Assim, o delineamento foi composto por 4 repetições de 20 miniestacas por unidade experimental, totalizando 80 miniestacas/espécie/coleta. O delineamento experimental utilizado foi inteiramente casualizado, num esquema fatorial de $4 \times 4$ (4 espécies $\times 4$ coletas seriadas), os resultados foram submetidos ao teste de homogeneidade pelo teste de Bartlett, posteriormente à análise de variância pelo teste $\mathrm{F}$, sendo as médias comparadas pelo teste de Tukey, ao nível de $5 \%$ de probabilidade.

\section{Minijardim de quatro espécies de Tibouchina}

O experimento foi conduzido em área a pleno sol do Laboratório de Macropropagação do Departamento de Botânica, da Universidade Federal do Paraná (UFPR), em Curitiba-PR, apresentando clima caracterizado como Cfb, segundo a classificação de Koppen-Geiger (PELL; FINLAYSON; MCMAHON, 2007), e irrigação intermitente por meio de microaspersão num intervalo de quatro vezes ao dia, por 6 minutos. O minijardim foi formado por quatro espécies do gênero Tibouchina, sendo, $T$. aff. fothergillae, $T$. sellowiana, $T$. moricandiana var. vinaceae e $T$. heteromalla, a partir de mudas produzidas previamente pela técnica de estaquia caulinar convencional na estação do outono/2015 (Figura 2). 


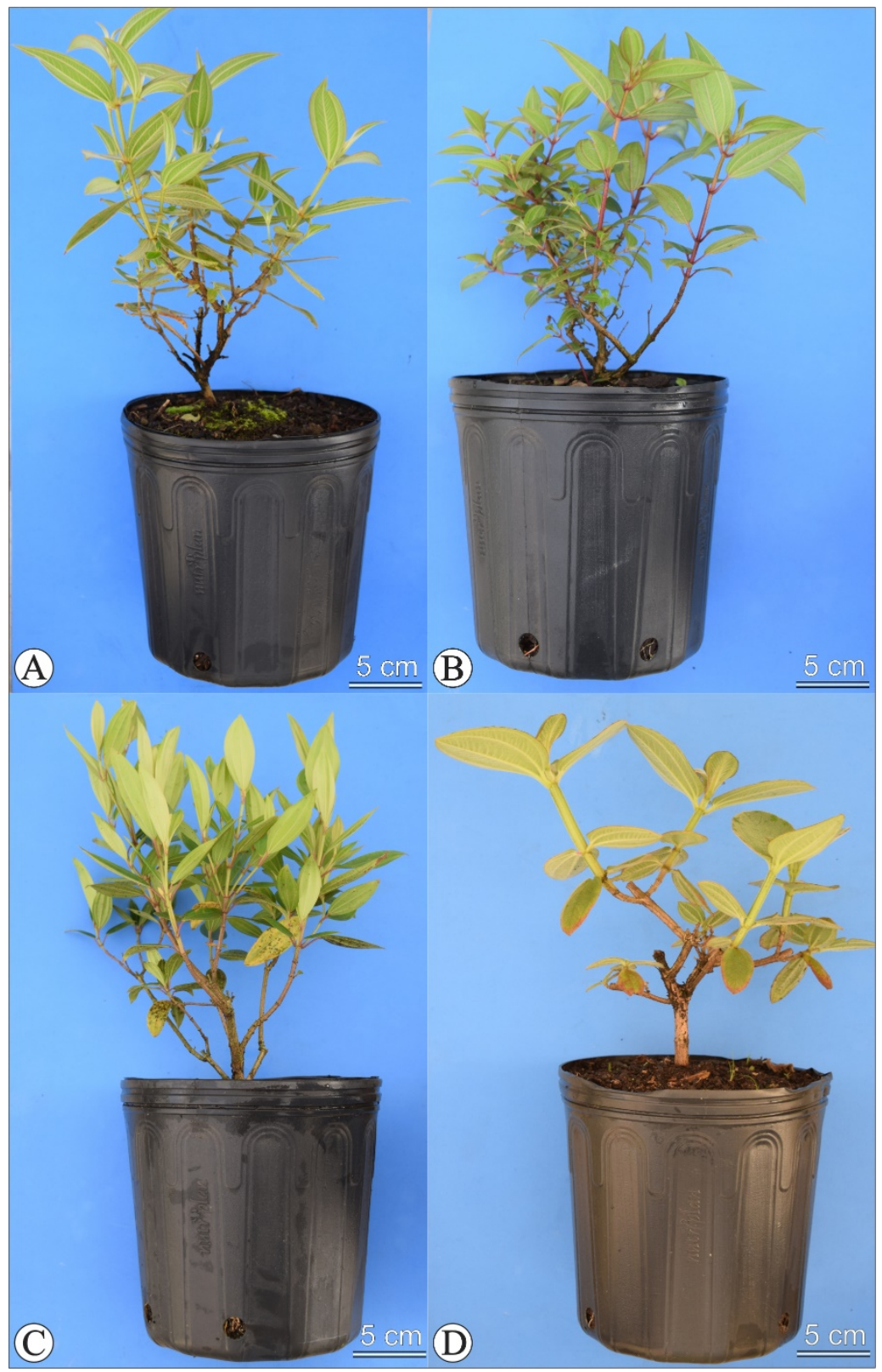

Figura 2: Minicepas utilizadas para confecção do experimento, sendo: A - T. aff. fothergillae; B - T. moricandiana var. vinaceae; C - T. sellowiana e D - T. heteromalla, Curitiba (Paraná).

As mudas que compuseram o minijardim foram conduzidas a pleno sol, em vasos com volume de $1 \mathrm{~L}$ contendo substrato comercial (com espaçamento de $10 \mathrm{~cm}$ entre minicepas, totalizando $1 \mathrm{~m}^{2}$ para produção de miniestacas/espécie, existindo 30 minicepas por espécie. A fertirrigação foi realizada quinzenalmente por meio de solução nutritiva, utilizando $50 \mathrm{ml}$ da solução por minicepa $(4 \mathrm{~g}$ $\mathrm{L}^{-1}$ de sulfato de amônio, superfosfato triplo, cloreto de potássio e $1 \mathrm{~g} \mathrm{~L}^{-1}$ de FTE BR-10 [7\% Zn, 4\% $\mathrm{Fe}, 4 \% \mathrm{Mn}, 0,1 \% \mathrm{Mo}, 2,5 \% \mathrm{~B}$ e $0,8 \% \mathrm{~B}])$.

Foi quantificada a produtividade de brotos, minicepas, brotações por minicepa (número de brotos passíveis de serem coletados em cada minicepa presente no minijardim) e o número de miniestacas por broto (miniestacas com $6 \mathrm{~cm}$ de comprimento, confeccionadas a partir dos brotos coletados das 
minicepas). $O$ delineamento experimental utilizado foi inteiramente casualizado, num esquema fatorial de $4 \times 4$ (4 espécies $\times 4$ coletas seriadas), os resultados foram submetidos ao teste de homogeneidade pelo Teste de Bartlett, posteriormente à análise de variância pelo Teste $F$, sendo as médias comparadas pelo Teste de Tukey, ao nível de $5 \%$ de probabilidade.

\section{Resultados e Discussão}

\section{Miniestaquia de quatro espécies de Tibouchina}

Após 35 dias de permanência em casa de vegetação foi verificada, segundo a análise de variância (ANOVA), a interação entre as variáveis miniestacas enraizadas (ME), número de raízes/miniestaca (NR), miniestacas com calos (MC), miniestacas mortas (MM), miniestacas brotadas (MB) e miniestacas que mantiveram as folhas iniciais (MMF) entre as espécies em diferentes momentos de coleta.

Para a variável ME, não houve diferença estatística entre as diferentes coletas para as espécies estudadas, salvo $T$. sellowiana que apresentou média estatisticamente superiores na Coleta $3 \mathrm{em}$ relação às demais coletas, demonstrando que a mesma apresenta menor índice rizogênico quando comparada às demais espécies, indicando tratar-se possivelmente de uma espécie de difícil enraizamento.

Pereira et al. (2015), estudando a rizogênese de T. moricandiana var. vinaceae, observaram valores que corroboram a atual pesquisa, no entanto os autores utilizaram a técnica de propagação vegetativa via estaquia caulinar. Portanto pode-se considerar que o uso da miniestaquia caulinar apresenta diversos benefícios, entre eles a redução do uso de reguladores vegetais, bem como a manutenção fitossanitária das minicepas a partir da adoção de minijardim.

As estações do ano são divididas em quatro momentos (outono, inverno, primavera e verão, respectivamente), porem as plantas sinalizam a mudança estacional normalmente no segundo mês de cada estação. Fato esse que leva a acreditar que $T$. sellowiana é mais responsiva ao enraizamento adventício em estações com temperaturas superiores.

Segundo Hartmann et al. (2011), estações com temperatura média inferiores acarretam o acúmulo de reservas no interior do vegetal, sendo estes utilizados posteriormente para diversos fins, como por exemplo a rizogênese. O NR foi estatisticamente superior para $T$. moricandiana var. vinaceae na coleta 2 , já para $T$. heteromalla as coletas 1 e 2 apresentaram médias estatisticamente superiores as coletas 3 e 4 . As demais espécies não apresentaram diferença estatística nas diferentes épocas de coleta.

Entre as espécies estudadas $T$. moricandiana var. vinaceae e $T$. aff. fothergillae apresentaram redução do NR na coleta 1 , não diferindo para as demais, demonstrando a importância das estações 
do ano para a variável. Já $T$. sellowiana apresentou médias estatisticamente inferiores em todas as coletas, com média geral de 1,24 raízes/miniestaca. Quando comparada com as demais espécies $T$. sellowiana possivelmente possa apresentar metabolismo lento, sendo que possivelmente o período em casa de vegetação foi curto.

Para CM T. sellowiana não apresentou diferença estatística entre as diferentes coletas. No entanto $T$. moricandiana var. vinaceae, T. heteromalla e $T$. aff. fothergillae apresentaram resultados estatisticamente superiores na coleta 2. Já entre as espécies, $T$. sellowiana apresentou reduzindo crescimento das estruturas raciais em relação as demais espécies.

A mortalidade de miniestacas foi elevada para T. sellowiana, onde as Coletas 1 e 2 apresentaram valores superiores quando comparadas às demais espécies. Os valores apresentados são inversamente proporcionais ao enraizamento, evidenciando que a espécie possivelmente pode ser definida como de difícil enraizamento.

Espécies de difícil enraizamento podem ou não apresentam níveis ideias de ácido indo acético (IAA), porém o que leva a grande dificuldade de propagação e a falta de um ou mais co-fatoes do enraizamento (HARTMANN et al., 2011). Substância denominadas co-fatores do enraizamento apresentam como função auxiliar o processo rizogênico, atuando em conjunto com a auxina e açúcares. Os principais co-fatores do enraizamento são os polifenois, ácido bórico, zinco e as antigiberelinas (HARTMANN et al., 2011).

No entanto ao longo do processo de rejuvenescimento, ou seja, das podas sucessivas e nutrição adequada, as quais as minicepas foram submetidas, houve redução da mortalidade, fato observado pelas coletas 3 e 4 , isso demostra que possivelmente houve o aumento da concentração de auxina e co-fatores do enraizamento nos tecidos vegetais.

Miniestacas de T. moricandiana var. vinaceae apresentaram maior mortalidade nas Coletas $2 \mathrm{e}$ 3, diferindo estatisticamente das demais coletas. Para T. aff. fothergillae e T. heteromalla, não houve diferença estatística, apresentando as mesmas menos de $1 \%$ de mortalidade. Em relação às espécies estudadas, foi encontrado um padrão de resposta, onde $T$. sellowiana apresentou a maior mortalidade entre as diferentes espécies ao longo das quatro coletas realizadas.

Dias et al. (2015), comparando diferentes tipos de miniestacas e substratos na propagação vegetativa de Anadenathera macrocarpa (Benth.) Brenan., concluíram que o uso de miniestacas oriundas da região apical em conjunto com o uso do substrato vermiculita são recomendados para a propagação vegetativa da espécie estudada. O uso do substrato adequado é de grande importância na propagação vegetativa de diversas espécies. O substrato ideal é aquele que retém água em quantidades aceitáveis pela planta, fornece ambiente escuro e aeração para a região basal do propágulo e oferece suporte para a planta. $\mathrm{O}$ uso de material inadequado pode favorecer o aumento da mortalidade da espécie (PIO et al., 2005).

Em pesquisa realizada por Zem, Zuffellato-Ribas e Koehler (2016), comparando o uso de diferentes substratos na propagação vegetativa de Pereskia aculeata Mill. nas quatro estações do 
ano, o uso do substrato Plantmax $®$ foi recomendado para propagação da espécie pesquisada, podendo a coleta do material vegetal ser realizada durante o ano todo. Na presente pesquisa, o uso do substrato comercial e vermiculita de granulometria fina na proporção 1:1 (v/v), apresentou boas condições para condução do experimento, apresentando todas as características citados por Pio et al. (2005), possivelmente auxiliando no processo rizogênico das diferentes espécies estudadas, bem como no desenvolvimento futuro do vegetal.

A manutenção das folhas iniciais é de grande importância na indução radicial, pois as folhas são centros de produção de hormônios e fotoassimilados, sendo estes elementos necessários para a indução e manutenção de raízes adventícias (ALVARENGA; CARVALHO, 1983; HARTMANN et al., 2011). Com relação à variável manutenção das folhas iniciais (MF), T. sellowiana não apresentou diferença estatística entre as médias das Coletas 1 e 2, sendo as mesmas estatisticamente inferiores às Coletas 3 e 4 , demostrando que ao longo das coletas existe uma maior manutenção das folhas iniciais.

Para T. sellowiana, a variável MF auxiliou positivamente no processo rizogênico, evidenciado um aumento estatisticamente significativo na Coleta 3 e 4 . Já, para T. moricandiana var. vinaceae há evidências que ao longo das coletas existe a redução da MF, ocorrendo diferença significativa entre as Coletas 1 e 4; no entanto esse fato não interferiu no processo rizogênico da espécie.

Para T. heteromalla não houve diferença estatística entre as diferentes coletas para variável MF. Já para Tibouchina aff. fothergillae houve diferença significativa nas Coletas 1 e 3 quando comparada às demais coletas, não existindo acréscimo/decréscimo na rizogênese da espécie. Portanto, para esta espécie, a manutenção de folhas iniciais não afeta a indução adventícia, podendo a mesma ser possivelmente classificada como de fácil enraizamento. Entre as espécies estudadas, $T$. sellowiana apresentou para MF médias inferiores às demais nas quatro coletas, salvo na Coleta 4 , onde $T$. sellowiana não diferiu estatisticamente de T. moricandiana var. vinaceae.

A média das brotações dos propágulos (MB) não diferiu estatisticamente para $T$. heteromalla e T. aff. fothergillae ao longo das coletas. Para T. moricandiana var. vinaceae as Coletas 1 e 4 apresentaram valores superiores em relação às demais. Para $T$. sellowiana houve diferença significativa na Coleta 4, sendo a mesma superior às demais coletas. Entre as diferentes espécies, $T$. sellowiana apresentou as menores médias ao longo das quatro coletas realizadas. 
Tabela 1: Comparação de médias da interação das variáveis miniestacas enraizadas (ME), número de raízes/miniestaca (NR), comprimento médio de raízes/miniestaca (CM), miniestacas mortas (MM), manutenção das folhas iniciais (MF) e miniestacas com brotação (MB) de T. moricandiana var. vinaceae, $T$. aff. fothergillae, $T$. sellowiana e $T$. heteromalla em quatro instalações seriadas, após 35 dias de permanências em casa de vegetação, Curitiba (Paraná).

\begin{tabular}{|c|c|c|c|c|c|}
\hline VAR & Tratamento & C 1 & C 2 & C 3 & C 4 \\
\hline \multirow{5}{*}{$\begin{array}{l}\text { ME } \\
(\%)\end{array}$} & T. moricandiana var. & 93,75 aA & $83,75 \mathrm{bA}$ & $83,75 \mathrm{bA}$ & $92,50 \mathrm{aA}$ \\
\hline & T. affinis fothergillae & $100,00 \mathrm{aA}$ & 100,00 aA & 98,75 aA & $97,50 \mathrm{aA}$ \\
\hline & T. sellowiana & $10,00 \mathrm{bB}$ & 11,25 cB & $26,25 \mathrm{cA}$ & $13,75 \mathrm{bB}$ \\
\hline & T. heteromalla & $100,00 \mathrm{aA}$ & $100,00 \mathrm{aA}$ & $97,50 \mathrm{aA}$ & $100,00 \mathrm{aA}$ \\
\hline & CV (\%) & \multicolumn{4}{|c|}{7,37} \\
\hline \multirow{5}{*}{ NR } & T. moricandiana var. & $7,22 \mathrm{bB}$ & $9,65 \mathrm{aA}$ & $6,63 \mathrm{aB}$ & $6,36 \mathrm{bB}$ \\
\hline & T. affinis fothergillae & $7,80 \mathrm{bA}$ & 9,26 aA & $8,13 \mathrm{aA}$ & $7,71 \mathrm{abA}$ \\
\hline & T. sellowiana & $1,62 \mathrm{cA}$ & $1,05 \mathrm{bA}$ & $1,41 \mathrm{bA}$ & $0,90 \mathrm{cA}$ \\
\hline & T. heteromalla & $12,11 \mathrm{aA}$ & $10,62 \mathrm{aAB}$ & $6,66 \mathrm{aC}$ & $9,31 \mathrm{aB}$ \\
\hline & CV (\%) & \multicolumn{4}{|c|}{17,89} \\
\hline \multirow{5}{*}{$\begin{array}{l}\text { CM } \\
(\mathrm{cm})\end{array}$} & T. moricandiana var. & $4,48 \mathrm{cB}$ & $9,80 \mathrm{cA}$ & $5,15 \mathrm{bB}$ & $5,00 \mathrm{bB}$ \\
\hline & T. affinis fothergillae & $7,14 \mathrm{bC}$ & $14,11 \mathrm{bA}$ & $10,80 \mathrm{aB}$ & $10,46 \mathrm{aB}$ \\
\hline & T. sellowiana & $2,22 \mathrm{dA}$ & $1,77 \mathrm{dA}$ & $0,76 \mathrm{cA}$ & $0,73 \mathrm{cA}$ \\
\hline & T. heteromalla & $9,82 \mathrm{aB}$ & $17,12 \mathrm{aA}$ & $10,84 \mathrm{aB}$ & $11,20 \mathrm{aB}$ \\
\hline & CV (\%) & \multicolumn{4}{|c|}{11,18} \\
\hline \multirow{5}{*}{$\begin{array}{l}\text { MM } \\
(\%)\end{array}$} & T. moricandiana var. & $6,25 \mathrm{bB}$ & $17,50 \mathrm{bA}$ & $17,50 \mathrm{bA}$ & $7,50 \mathrm{bB}$ \\
\hline & T. affinis fothergillae & $0,00 \mathrm{cA}$ & $0,00 \mathrm{cA}$ & $1,25 \mathrm{cA}$ & $2,50 \mathrm{cA}$ \\
\hline & T. sellowiana & $90,00 \mathrm{aA}$ & $88,75 \mathrm{aA}$ & $68,75 \mathrm{aB}$ & $68,75 \mathrm{aB}$ \\
\hline & T. heteromalla & $0,00 \mathrm{cA}$ & $0,00 \mathrm{cA}$ & $2,50 \mathrm{cA}$ & $0,00 \mathrm{cA}$ \\
\hline & CV (\%) & \multicolumn{4}{|c|}{9,53} \\
\hline \multirow{5}{*}{$\begin{array}{l}\text { MF } \\
(\%)\end{array}$} & T. moricandiana var. & $90,00 \mathrm{bA}$ & $53,75 \mathrm{cB}$ & $58,75 \mathrm{bB}$ & $36,25 \mathrm{bC}$ \\
\hline & T. affinis fothergillae & 99,25 aA & $86,25 \mathrm{bC}$ & 97,50 aAB & $88,75 \mathrm{aBC}$ \\
\hline & T. sellowiana & $8,75 \mathrm{cB}$ & $11,25 \mathrm{~dB}$ & $23,75 \mathrm{cA}$ & $32,25 \mathrm{bA}$ \\
\hline & T. heteromalla & $97,50 \mathrm{abA}$ & 99,25 aA & $95,00 \mathrm{aA}$ & $91,25 \mathrm{aA}$ \\
\hline & CV (\%) & \multicolumn{4}{|c|}{7,15} \\
\hline \multirow{5}{*}{$\begin{array}{l}\text { MB } \\
(\%)\end{array}$} & T. moricandiana var. & $91,25 \mathrm{bA}$ & $82,50 \mathrm{bB}$ & $82,50 \mathrm{bB}$ & $92,50 \mathrm{bA}$ \\
\hline & T. affinis fothergillae & 100,00 aA & $100,00 \mathrm{aA}$ & $96,25 \mathrm{aA}$ & 96,25 abA \\
\hline & T. sellowiana & $7,50 \mathrm{cC}$ & $10,00 \mathrm{cC}$ & $23,75 \mathrm{cB}$ & $30,50 \mathrm{cA}$ \\
\hline & T. heteromalla & $100,00 \mathrm{aA}$ & $100,00 \mathrm{aA}$ & $97,50 \mathrm{aA}$ & $100,00 \mathrm{aA}$ \\
\hline & CV (\%) & \multicolumn{4}{|c|}{3,7} \\
\hline
\end{tabular}

Médias seguidas da mesma letra minúscula na vertical e médias seguidas da mesma letra maiúscula na horizontal, não diferem significativamente entre si pelo teste de Tukey a 5\% de probabilidade. CV: Coeficiente de variação; VAR: Variável; As coletas ocorreram em setembro/2015 (C1), novembro/2015 (C2), janeiro/2016 (C3) e março/2016 (C4). 


\section{Minijardim de quatro espécies de Tibouchina}

Segundo a análise de variância (ANOVA), houve interação dupla para as variáveis Brotos, Miniestacas, Brotos/Minicepa e Miniestacas/Brotos entre as diferentes coletas e espécies de Tibouchina. Demonstrando que as variáveis são dependentes entre si (Tabela 2).

Tabela 2: Comparação de médias da interação das variáveis: brotos, miniestacas, brotos/minicepas e miniestacas/broto, a partir de quatro coletas realizadas ao longo do ano, Curitiba (Paraná).

\begin{tabular}{|c|c|c|c|c|c|c|c|c|c|}
\hline \multirow[b]{2}{*}{ Variáveis } & \multirow[b]{2}{*}{ Coletas } & \multicolumn{8}{|c|}{ Tibouchina spp } \\
\hline & & \multicolumn{2}{|c|}{$\begin{array}{c}T . \\
\text { heteromalla }\end{array}$} & \multicolumn{2}{|c|}{$\begin{array}{c}T . \\
\text { moricandiana } \\
\text { var. vinaceae }\end{array}$} & \multicolumn{2}{|c|}{$\begin{array}{c}\text { T. aff. } \\
\text { fothergillae }\end{array}$} & \multicolumn{2}{|c|}{$\begin{array}{c}T . \\
\text { sellowiana }\end{array}$} \\
\hline \multirow{5}{*}{$\begin{array}{l}\text { BROTOS } \\
\left(\mathbf{N}^{\circ}\right)\end{array}$} & 1 & 10,00 & $\mathrm{cA}$ & 8 & $\mathrm{cA}$ & 10,00 & $\mathrm{cA}$ & 11,80 & $\mathrm{aA}$ \\
\hline & 2 & 26,60 & $a b A$ & 27,00 & $\mathrm{bA}$ & 22,80 & $\mathrm{bAB}$ & 18,60 & $\mathrm{aB}$ \\
\hline & 3 & 33,60 & $\mathrm{aA}$ & 36,00 & $a A$ & 25,00 & $a b B$ & 16,40 & $\mathrm{aC}$ \\
\hline & 4 & 25,80 & bB & 45,60 & $a A$ & 30,20 & $a A B$ & 11,80 & $\mathrm{aC}$ \\
\hline & CV (\%) & \multicolumn{8}{|c|}{19,54} \\
\hline \multirow{5}{*}{$\begin{array}{l}\text { MINIESTACAS } \\
\left(\mathbf{N}^{\circ}\right)\end{array}$} & 1 & 18,60 & $\mathrm{cA}$ & 13,80 & $\mathrm{cA}$ & 8,20 & $\mathrm{cA}$ & 16,20 & $\mathrm{aA}$ \\
\hline & 2 & 32,00 & bA & 33,60 & $\mathrm{bA}$ & 32,80 & bA & 18,80 & $\mathrm{aB}$ \\
\hline & 3 & 48,20 & $\mathrm{aA}$ & 51,40 & $a A$ & 29,20 & bB & 16,20 & $\mathrm{aC}$ \\
\hline & 4 & 38,20 & $a b B$ & 53,00 & $a A$ & 48,40 & $a A B$ & 16,40 & $\mathrm{aC}$ \\
\hline & CV (\%) & \multicolumn{8}{|c|}{21,12} \\
\hline \multirow{5}{*}{$\begin{array}{c}\text { BROTOS/MINICEPA } \\
\left(\mathbf{N}^{\circ}\right)\end{array}$} & 1 & 1,66 & $\mathrm{cA}$ & 1,33 & $\mathrm{cA}$ & 1,66 & $\mathrm{cA}$ & 1,96 & $\mathrm{aA}$ \\
\hline & 2 & 4,43 & $a b A$ & 4,50 & $\mathrm{bA}$ & 3,80 & $\mathrm{bAB}$ & 3,10 & $\mathrm{aB}$ \\
\hline & 3 & 5,60 & $a A$ & 6,00 & $a A$ & 4,16 & $a b B$ & 2,73 & $\mathrm{aC}$ \\
\hline & 4 & 4,30 & bB & 5,93 & $a A$ & 5,03 & $a A B$ & 1,96 & $\mathrm{aC}$ \\
\hline & CV (\%) & \multicolumn{8}{|c|}{19,54} \\
\hline \multirow{5}{*}{$\begin{array}{c}\text { MINIESTACAS/BROTO } \\
\left(\mathbf{N}^{\circ}\right)\end{array}$} & 1 & 1,87 & $\mathrm{aA}$ & 2,03 & $\mathrm{aA}$ & 0,79 & $\mathrm{bC}$ & 1,36 & $\mathrm{aB}$ \\
\hline & 2 & 1,20 & bA & 1,23 & $\mathrm{bA}$ & 1,45 & $\mathrm{aA}$ & 1,00 & $\mathrm{aA}$ \\
\hline & 3 & 1,45 & $a b A$ & 1,42 & $\mathrm{bAB}$ & 1,19 & $a b A B$ & 0,98 & $\mathrm{aB}$ \\
\hline & 4 & 1,48 & $a b A$ & 1,49 & $\mathrm{bA}$ & 1,59 & $\mathrm{aA}$ & 1,41 & $\mathrm{aA}$ \\
\hline & CV (\%) & \multicolumn{8}{|c|}{19,99} \\
\hline
\end{tabular}

Médias seguidas da mesma letra minúscula na vertical e médias seguidas da mesma letra maiúscula na horizontal, não diferem estatisticamente entre si pelo Teste de Tukey a $1 \%$ de probabilidade. CV (\%): Coeficiente de variação em porcentagem. As coletas ocorreram em setembro/2015 (C1), novembro/2015 (C2), janeiro/2016 (C3) e março/2016 (C4).

As brotações na $1^{\circ}$ coleta não apresentou diferença estatística entre as espécies, no entanto a $2^{\circ}$ coleta demonstra que $T$. heteromalla, $T$. moricandiana var. vinaceae e $T$. fothergillae são estatisticamente superiores a $T$. sellowiana. Na $3^{\circ}$ coleta observa-se que $T$. heteromalla e $T$. moricandiana var. vinaceae apresentaram a maior produção de brotos quando comparadas com as demais espécies. Na $4^{\circ}$ coleta $T$. moricandiana var. vinaceae e $T$. aff. fothergillae produziram maior quantidade de brotos. De modo geral $T$. sellowiana apresentou o menor número de brotos ao longo das coletas realizadas, salvo na $1^{\circ}$ coleta. 
Para T. heteromalla, foi possível observar aumento estatístico na produção de brotos até a $3^{\circ}$ coleta, demostrando que a espécie possivelmente atingiu o limite de produção de brotos, fato este observado por conta do início da redução da produção de brotos na última coleta. Já para $T$. moricandiana var. vinaceae e T. aff. fothergillae, foi possível inferir que são espécies de elevada brotação, pois ambas apresentam mesmo padrão de resposta, ou seja, iniciam a produção de brotos com números reduzidos e ao longo das coletas aumentam a produção de brotos.

É valido ressaltar que a produção de brotos e miniestacas podem reduzir dependendo das médias climáticas que o momento de coleta apresentar, ou seja, momentos com fotoperíodo diário e temperatura média reduzidos sinalizam o possível início do acúmulo de açúcares e proteínas no interior dos elementos crivados, podendo os mesmos terem sido obstruídos pela proteína $\mathrm{P}$ (HARTAMANN et al., 2011). T. sellowiana foi a única espécie que apresentou linearidade ao longo das diferentes coletas em relação a variável brotos, não apresentando diferença estatística entre as coletas, independente das estações do ano, demonstrando ser uma espécie que não responde a alteração no fotoperíodo e variações ambientais.

Para a variável miniestacas na $1^{\circ}$ coleta não houve diferença na produção de miniestacas entre as espécies, já para $2^{\circ}$ coleta observou-se que $T$. heteromalla, $T$. moricandiana var. vinaceae e $T$. aff. fothergillae se destacaram na produção de miniestacas, sendo estatisticamente superiores a $T$. sellowiana. $\mathrm{Na} 3^{\circ}$ coleta é possível perceber que $T$. heteromalla e $T$. aff. fothergillae foram superiores as demais espécies. Na $4^{\circ}$ coleta $T$. sellowiana apresentou a menor produção de miniestacas quando comparada com as demais espécies.

Para T. heteromalla é possível perceber que a produção de miniestacas aumenta até a $3^{\circ}$ coleta, iniciando assim uma possível redução observada pela igualdade estatística entre a $2^{\circ}$ e $4^{\circ}$ coleta. $T$. moricandiana var. vinaceae e $T$. aff. fothergillae apresentam respostas semelhantes na produção de miniestacas, iniciando a produção com menores valores e ao longo das coletas, aumentam a produção. Já $T$. sellowiana não existe diferença estatística entre as coletas.

Para a variável brotos/minicepas na $1^{\circ}$ coleta não houve diferença estatística entre as espécies, no entanto a $2^{\circ}$ Coleta $T$. sellowiana apresentou a menor média, não diferindo estatisticamente de $T$. aff. fothergillae. A $3^{\circ}$ Coleta foi marcada pela menor média obtida por $T$. sellowiana, diferindo estatisticamente entre as demais espécies. $\mathrm{Na} 4^{\circ}$ coleta obteve-se superioridade estatística para $T$. moricandiana var. vinaceae e T. aff. fothergillae em relação as demais espécies. Para T. heteromalla houve um aumento gradativo até o pico de produção que ocorreu na $3^{\circ}$ coleta, já na $4^{\circ}$ coleta iniciouse o declínio da produção. T. moricandiana var. vinaceae e T. aff. fothergillae apresentaram as maiores médias na $3^{\circ}$ e $4^{\circ}$ coleta não diferindo estatisticamente entre si. Para $T$. sellowiana não foi observado mudanças estatisticamente significativas entre as diferentes coletas.

Para produção de miniestacas/broto não foi observado diferença estatística na $2^{\circ} \mathrm{e} 4^{\circ}$ coleta entre as diferentes espécies de Tibouchina. Já a $1^{\circ}$ coleta foi marcada pelas maiores médias de $T$. heteromalla e T. moricandiana var. vinaceae e a menores médias para T. fothergillae. Na $3^{\circ}$ coleta 
existe diferença estatística apenas entre $T$. heteromalla e $T$. sellowiana. $T$. heteromalla a produção de miniestacas/broto foi parcialmente linear, senão fosse pela redução na $2^{\circ}$ coleta. T. moricandiana var. vinaceae apresentou a maior média apenas na $1^{\circ}$ coleta, sendo que as demais coletas foram reduzidas, porém não diferenciaram estatisticamente entre si. T. aff. fothergillae apresentou crescimento entre as diferentes coletas e $T$. sellowiana não demonstrou diferença estatística entre os momentos de coleta.

A manutenção de minicepas de Acer palmatum Trunb., bem como a manutenção do vigor dos futuros progágulos oriundos de tais minicepas, é indicado o cultivo das mesmas em área com plena luz solar com fertirrigação controlado (STUEEP et al., 2016). Segundo Wendling et al. (2010), para garantir qualidade e homogeneidade na produção das minicepas, é de suma importância o balanço nutricional das espécies.

\section{Conclusão}

Nas condições que a presente pesquisa foi realizada, o uso de miniestacas na propagação vegetativa das espécies Tibouchina affinis fothergillae, T. moricandiana variedade vinaceae e $T$. heteromalla faz com que as mesmas possam ser consideradas espécies de fácil enraizamento (> $80 \%$ de enraizamento), não variando a resposta frente ao rejuvenescimento seriado. Já $T$. sellowiana, pode ser considerada uma espécie de difícil enraizamento, onde a técnica de rejuvenescimento seriado favoreceu o enraizamento adventício. Para produção de miniestacas é recomendado a $1^{\circ}$ coleta para $T$. heteromalla e $T$. moricandiana var. vinaceae. Para $T$. aff. fothergillae a $4^{\circ}$ coleta e, $T$. sellowiana pode ser coletada a qualquer momento.

\section{Referências}

ALVARENGA, L. R.; CARVALHO, V. D. Uso de substâncias promotoras de enraizamento de estacas frutíferas. Informe Agropecuário, v. 9, n. 101, p. 47-55, 1983.

BADILLA, Y. et al. IBA Efficiency on Mini-Cutting Rooting From Teak (Tectona grandis Linn F.) Clones. Revista Árvore, Viçosa, v. 4, n. 3, p.477-488, mai. /jun. 2016.

CÉSAR, T. M. et al. Estaquia e alporquia de Tibouchina Fothergillae (D.C) Cogn (Melastomataceae) com aplicação de ácido naftaleno acético. Revista Scientia Agraria, Curitiba, v. 10, n. 6, p. 463-468, nov. /dez. 2009.

CLAUSING, G; RENNER, S. S. Molecular phylogenetics of Melastomataceae and Memecylaceae: implications for character evolution. American Journal of botany, Missouri, v. 88, n. 3, p. 486-498, mar. 2001. 
DIAS, P. C. et al. Tipos de miniestaca e de substrato na propagação vegetativa de Angico-Vermelho (Anadenanthera macrocarpa (Benth.) Brenan). Revista Ciência Florestal, Santa Maria, v. 25, n.4, p.909-919, out. /dez. 2015.

HARTMANN, H. et al. Hartmann \& Kester's Plant Propagation: principles and practices. 8th. New York: Englewood Clipps, 2002.

LORENZI, H. Plantas ornamentais no Brasil: arbustivas, herbáceas e trepadeiras. 4. ed. Nova Odessa: Instituto Plantarum, 2008.

MEYER, F. S. O Gênero Tibouchina Aubl. (Melastomataceae) no Estado do Paraná, Brasil. 114 f. Dissertação (Mestrado em Botânica) - Setor de Ciências Biológicas, Universidade Federal do Paraná, Curitiba, 2008.

PEEL, M. C.; FINLAYSON, B. L.; MCMAHON, T. A. Updated world map of the K"oppen-Geiger climate classification. Hydrology and Earth System Sciences Discussions, European Geosciences Union, 2007, 11 (5), pp.1633-1644.

PERALTA, P. Las espécies del gênero Tibouchina (Melastomataceae) en Argentina. Darwiniana, Buenos Aires, v. 40, n. 1-4, p. 107-120, jan. 2002.

PEREIRA, M. O. et al. Enraizamento de estacas de Tibouchina moricandiana var. vinaceae em função da forma de aplicação e concentrações de AlB. Revista de Ciências Agroveterinárias, Lages, v. 14. n. 3. p. 210-216, 2015. DOI: 10.5965/223811711432015210

PIO, R. et al. Substratos no enraizamento de estacas herbáceas de figueira oriunda da desbrota. Revista de Ciência e Agrotecnologia, Lavras, v. 29, n. 3, p. 604-609, jun. 2005.

RENNER, S. S. A survey of reproductive biology in neotropical Melastomataceae na Memecylaceae. Annals of the Missouri Botanical Garden, Missouri, v. 76, n. 2, p. 496-518, 1989.

SILVA, C.V.; AFFONSO, P. Levantamento da Tibouchina AUBL (Melastomataceae) no parque estadual da serra do mar. Núcleo Curucutu, São Paulo, v. 17, n. 2, p. 195-206, 2005.

STUEPP, C. A. et al. Ex vitro system for Acer palmatum plants propagation by mini-cuttings technique. Revista Cerne, Lavras, v. 22, n. 3, p.355-364, jul./ sep. 2016.

WENDLING, I. et al. Mini-cuttings technique: a new ex vitro method for clonal propagation of sweetgum. New Forests, 2010. v. 39, p. 343-353.

XAVIER, A.; SANTOS, G. A. dos. Clonagem em espécies florestais nativas. In: ROCHA, M. G. B. Melhoramento de espécies arbóreas nativas. Belo Horizonte: Instituto de Desenvolvimento Florestal Sustentável - IEF, 2002.

ZEM, L. M.; ZUFFELLATO-RIBAS, K. C.; KOEHLER, H. S. Enraizamento de estacas semilenhosas de Pereskia aculeata nas quatro estações do ano em diferentes substratos. Revista Eletrônica Científica da UERGS, Porto Alegre, v. 2, n. 3, p. 227-233, nov. 2016. Disponível em: < http://revista.uergs.edu.br/index.php/revuergs/article/view/487/82.> Acesso em: 06 abr. 2017. 